Holmes, i.e., that it is due to survival of the cortical macular area owing to its potential double blood supply from the middle as well as from the posterior cerebral artery. Henschen has also pointed out that the optic radiation in its posterior part receives deep twigs from the middle cerebral artery. The terminal branches of these arteries anastomose freely in the pia mater, but the penetrating twigs are end arteries. In this way initial division of the fixation area followed by sparing is easily accounted for, and isolated homonymous hemianopic scotomata may be explained on the assumption that the block has occurred in one or several penetrating twigs distal to the pial anastomosis.

The functional superiority of the macular neurones also suggests that a greater degree of interference may be required to put them completely out of action, whether it is caused by vascular disease or by pressure on the radiation by a tumour. For these reasons it seems unnecessary to postulate a double cortical representation for the macular area although this hypothesis is advocated by such recognized authorities as Wilbrand and Saenger. As regards central scotomata it would appear that the macular cells and fibres are in reality extremely resistant, and that their liability to interference depends upon anatomical and circulatory conditions and on selective affinities for toxins rather than upon functional relationships.

\title{
A SERIES OF 250 CATARACT EXTRACTIONS BY BARRAQUER'S METHOD*
}

BY

\author{
MAJOR R. E. WRIGHT, I.M.S.
}

SUPERINTENDENT, GOVERNMENT OPHTHALMIC HOSPITAL, MADRAS

THE method of removing the cataractous lens in its capsule by means of a suction apparatus, as perfected by Barraquer, attracted a large amount of attention throughout the ophthalmological world shortly after it was described and demonstrated. As in numerous other clinics the method was put on its trial here as soon as practicable.

In 1922-23 a series of 250 cases was completed. The operations did not run consecutively but parallel with the routine "Madras" operation (primary capsule rupture with complete iridectomy) and

* From material collected for and included in the Annual Report of the Superintendent, Government Ophthalmic Hospital, Madras for 1922. 
a series of "Simple"" operations. The tabular statement shows this Barraquer series compared with 1,279 other operations done in 1922. The results are classed as they usually are in this clinic :

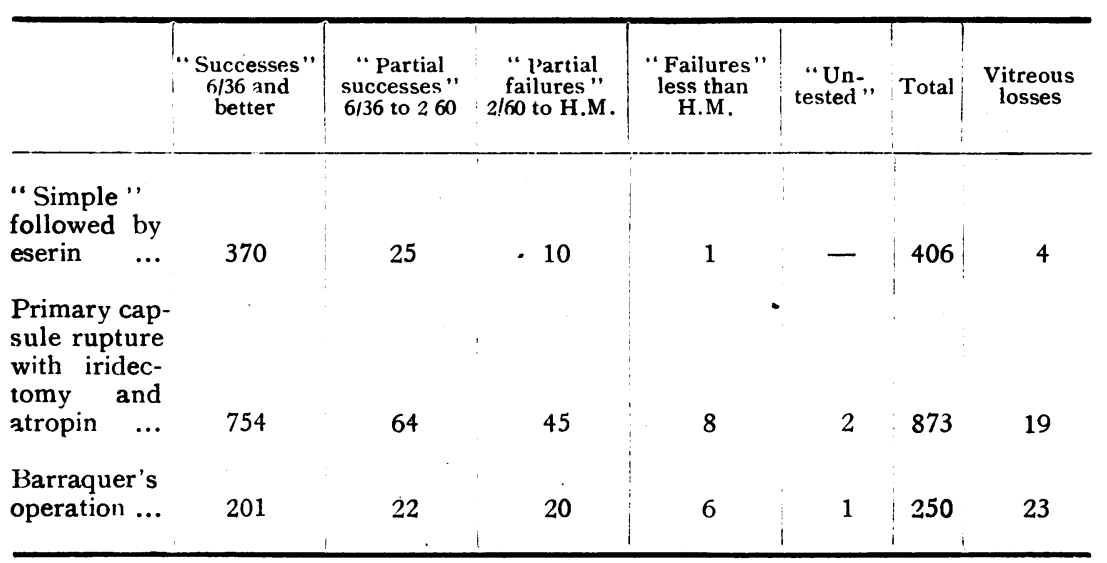

It may be seen that the results are very much worse than in the case of our ordinary capsulotomy method, but this is hardly a fair comparison. A definite opinion on the value of any method of cataract operating cannot be formed on such a series as this, and it was obvious that the later results tended to become better. One got the impression, however, that phakoeresis is probably more valuable than any other method yet introduced for the removal of the lens in its capsule in selected cases, but there is a large number of cases in which the method is inapplicable. It will hardly give a sufficiently high percentage of "operative" successes to justify its adoption in the following types of cases :

(a) A markedly bulging eye.

(b) A friable capsule.

(c) An immature cataract with a normal suspensory ligament.

(d) A Morgagnian cataract.

Other more uncommon types too might be enumerated in which it would be infinitely wiser not to use the method, and in so far as the "operative" and "immediate post-operative" results are concerned it is still beyond doubt that the surgeon must select his operation according to the case and not allow himself to be tied down to any particular method even though he prefers a certain type of operation for the general run of his cases.

In my experience one of the most important pitfalls into which the beginner is liable to stumble is allowing the cup to become engaged in the iris. It is absolutely essential that the pupil should 
be fully dilated, or an iridectomy be done, if the operator has any difficulty in applying the cup to the anterior capsule. I have frequently found difficulty in keeping the cup clear of the pupillary border either in cases where full dilatation was not obtained or in cases where the iris contracted as the result of making the section. It may here be mentioned that many of our cases dilate to a very limited extent with the usual pre-operative instillations of atropin 1 per cent. Such cases are not suitable for Barraquer's operation without iridectomy. When, with Barraquer's method, a perfect delivery is effected through a non-injured pupil, and negative pressure is established subsequent to delivery with complete reposition of the pupil, one may consider that the most perfect "operative" result has been achieved in so far as the intra-capsular method is concerned. If, thereafter, the "immediate post-operative" period is gone through without mishap, that is to say that without an iris prolapse the section heals, the chamber forms, and we get a round active pupil, the same may be said of the "immediate post-operative" result.

The cases constituting this series have not been examined at a sufficiently long interval after operation to give an opinion on the remote post-operative results. There are, however, certain factors bearing on the ultimate result which deserve serious consideration. I have always considered that the greatest and most far reaching difference between any intra-capsular method and the capsulotomy method (other things being equal) is that the vitreous body is deprived of the support of the suspensory ligament and capsule, a partition which not only serves to retain the vitreous in position and allows the posterior chamber to form, but which prevents to a large extent invasion of the vitreous by cell elements which give rise to vitreous opacities. The remote changes to which the vitreous is liable as the result of this deprivation is the test by which the intra-capsular method must eventually stand or fall in those cases in which it is admittedly the operation of choice from a purely technical point of view. There are many unpleasant possibilities to look forward to when the eye is in this condition. Firstly, the mechanical effects of the undamaged vitreous body pushing forward against the iris must be considered; and if the hyaloid membrane is damaged, as it frequently is, there are additional disadvantages associated with the approximation of the vitreous to the region of the section (in a combined operation), and the localized hernia into the anterior chamber (in a "Simple"). Secondly, we must bear in mind the possible effects on aqueous secretion and circulation of not only the altered position of the vitreous body, but also of the damage to the ciliary epithelium from dragging on the suspensory fibres when the lens is torn free. The effects of traumatizing the ciliary body in this way as regards those 
cellular elements.from which the suspensory fibres are derived (about whose activities we know very little), and also the possibility of stirring up definite precursors of fibro-blastic activity, has not been sufficiently considered from the point of view of late results. A study of coronal sections through the ciliary region on the one hand, and a series of specimens of gross staphylomata of the cornea with the suspensory capsule barrier in position and healthy posterior segments on the other, has given me the impression that as long as the suspensory capsule barrier is intact the posterior segment may remain healthy under the most adverse circumstances, but that damage to the suspensory ligament and ciliary body is very liable to be followed by pathological conditions of the posterior segment. The great drawback about the formation of opacities in the vitreous and interference with vision thereby as compared with the formation of capsular opacities (after-cataract), is, that after-cataract is compatible with a healthy posterior segment, and may, with care, be relieved, whereas vitreous opacities of an organized type tend to be progressive and incurable. It may be contended that a needling for after-cataract inflicts just as much trauma on the ciliary body as the dragging out of a lens in its capsule, and that after needling the vitreous is herniated into the anterior chamber. For this reason I deliberately use the words "with care." Needling of a capsule as frequently performed is certainly open to such an objection. I will not go into detail as to how needling is effected in this clinic; it is done with a Bowman's needle with the utmost care, without dragging but rather with a series of consecutive stabs or lifts with the extreme point of the needle. The smallest aperture is effected which will give good vision; for preference the lenticular or broadly ovoid aperture is placed obliquely down and in.

From time to time I have examined a number of cases in which an apparently perfect intra-capsular operation has been performed and I have rarely seen one free from vitreous opacities. I have no doubt that in Madras we deal with a type of case which is very much more liable to reaction than is met with, for instance, in Europe or America, and for this reason one cannot form a true opinion as to the ultimate results of leaving the vitreous unsupported by the suspensory capsule diaphragm. I am aware that numbers of experienced observers report excellent visual results after removing the lens in its capsule, and not only good results shortly after operation but for periods of years. Still, in spite of this, I am almost persuaded that in so far as our cases are concerned, where no selection is made and constitutional disease does not constitute a contra-indication to operation, it frequently happens that the vitreous left exposed with only the very delicate (and sometimes torn or non-existent) hyaloid to 
protect it, is invaded by cellular elements thrown into activity by the trauma of operation. In investigating this question I formerly made a considerable number of examinations with the Gullstrand slit-lamp and corneal microscope after the method of Professor Vogt and observed that even in perfect "operative" and "immediate post-operative" results with Barraquer's technique (or any other intra-capsular technique) examination at the time of discharge (14 to 21 days after operation) almost invariably revealed masses of pigment not only on the surface of the vitreous but extending back into the substance of the vitreous and also various types of vitreous opacities. It was impossible to say whether these masses of pigment represented collections of migrating melanoblasts or merely tiny deposits of free pigment, but in certain cases it appeared that cells were undoubtedly migrating and giving rise to delicate fibrillar net-works which radiated backwards through the vitreous body.

Since then I have had the advantage of attending Professor Vigt's course on slit-lamp microscopy, and now realize that many of the vitreous opacities which I formerly observed were not of such serious import as I had imagined. In fact it is quite compatible with a healthy vitreous to see several types of structural opacifications with the microscope. It is also quite a common occurrence to see masses of pigment disseminated throughout the anterior and posterior chambers, on the surface of the hyaloid, and in the prolapsed vitreous after an intra-capsular operation, the significance of which may not be of great importance. This being so I have to a certain extent modified my ideas, expressed before now in the annual reports of this hospital, as to the prognostic importance of post-operative vitreous opacities. There is, however, in any operation where the globe is opened, bloodvessels and connective tissue damaged, and the vitreous exposed, the possibility of fibroblastic invasion. The manner in which the vitreous is affected by traumatism unassociated with bacterial invasion is most important. My general impression from the observation of numbers of specimens is that the vitreous, once invaded by cellular elements, is liable to eventual opacities of a serious progressive nature, and that opacities of this type once formed are unalterable. It is not contended that there is no such thing as amorphous vitreous opacities capable of undergoing absorption either spontaneously or in association with some form of treatment, but the possibilities referred to here do not come under this head. The type of vitreous change which is referred to is that associated with trauma and with the possibility of cells being set free which invade this structure, such as rupture of a retinal vessel, or the penetration of the posterior segment by a foreign body which carries mesoblastic cellular elements in its 
track, or the performance of a section on the anterior segment which removes the capsule and suspensory from the vitreous in front and allows the cellular elements of the traumatized tissues access to the vitreous itself. The hyaloid evidently is frequently ruptured even in the most favourable cases, although it is often possible to demonstrate the fossa patellaris by means of the irrigator after a favourable intra-capsular operation. After the section has healed rupture of the hyaloid is sometimes evidenced by the fact of a mushroom-like mass of jelly protruding through the pupillary aperture covered with gold-dust-like pigment spots and permeated by fine opaque fibrillar strands. At times one sees a formed posterior chamber with an apparently intact hyaloid covered with fine gold-dust-like pigment points.

It is difficult to understand why vitreous fibrils should become opaque when unassociated with fibroblastic activity. It is presumably a physical change making itself evident in an altered refractive state. That dense progressive fibrillar opacities do occur after the type of trauma referred to above in which fibroblastic activity cannot be demonstrated, is a familiar fact. It seems reasonable enough to suppose that the main mass of the vitreous is merely extra-cellular material derived from cell bodies for the most part situated in the region of the ciliary body and ora serrata, and that actual vitreous itself does not contain cells, but is a derivative of cells so situated, which throw out long processes of a very delicate nature which hold a semi-fluid matrix in their interstices. These, in different positions, give rise to different appearances, such as the fibrils which run forward to become continuous with or from the suspensory ligament itself, and those which, welded together, dip behind the lens to form the delicate homogeneous hyaloid and line the patellar fossa. It must not be forgotten that in traumatizing the suspensory ligament we are traumatizing that region from which the solid elements of the vitreous itself spring, which is for all practical purposes identical in origin with the enveloping membrane and radiating transparent solid fibrillar portions of the vitreous mass. It is unnecessary further to draw the attention of those who are interested in this matter to the great importance of treating the vitreous with respect in all operative procedures on the eye. In this clinic we regard an eye as potentially lost in which a vitreous escape of any kind has occurred or in which vitreous comes to lie against the back of the section; or even when there is a hammock-shaped drawn-up pupil with pillars rolled backwards and the vitreous occupying a plane anterior to the iris in the upper third of the anterior chamber. Those who appear to regard vitreous traumata of various kinds as a mere incident, undesirable in nature, but of no great importance as regards eventual prognosis, should follow up and 
carefully study the changes which take place in the vitreous as the result of the development of fibrillar streamers from the region of an operative trauma. In cataract work the eventual test of such vitreous changes is of course the vision, and it must be confessed that many cases in which there is considerable vitreous change on microscopic and ophthalmoscopic investigation, preserve fairly good vision for a considerable time. Strictly speaking, the result of an operation for cataract ought to be recorded at least twelve months after the section. In this way only will the truth be arrived at as to the permanent and lasting value of any method. This is a very difficult matter in India, but no difficulty ought to be experienced in gradually collecting large figures in other countries where hospital cases are more easily kept in view. If only the perfect "operative" and "immediate post-operative" results were followed up the figures would be strictly comparable. In making these statements I do not lose sight of the fact that it is better for a patient to have vitreous opacities and a gradually darkening eye than not to have vision at all. The danger of the development of vitreous opacities after removing the lens in its capsule may not be so important as would appear from the foregoing when applied to selected eyes, healthy except for cataract, such as are usually chosen for operation in Western clinics, but even then one has to consider the other effects of leaving the vitreous unsupported, as suggested at the beginning of this note. Time and the accurate records of carefully followed cases wilı tell.

\title{
A NOTE ON PULFRICH'S PHENOMENON WITH A SUGGESTION ON ITS POSSIBLE CLINICAL IMPORTANCE
}

BY

\author{
H. GRIMSDale \\ LONDON
}

ABout eighteen months ago, Mr. J. H: Tomlinson drew my attention to the curious phenomenon which Pulfrich had recently described, and gave me a small model on which the phenomenon could be demonstrated.

It will be remembered that Pulfrich had noted the fact that if one eye has its light sense diminished by covering with a dark glass, the image from this eye is recognized by the brain more slowly than the image from the normal eye. 